Article

\title{
Sensing Atrazine Herbicide Degradation Products through Their Interactions with Humic Substances by Surface-Enhanced Raman Scattering
}

\author{
Giulia Zanasi ${ }^{1}$, Rafael J. G. Rubira ${ }^{2, *}$, Ornella Francioso ${ }^{1}$, Maria Vega Cañamares ${ }^{3} \mathbb{C}$, Carlos J. L. Constantino ${ }^{2}$ \\ and Santiago Sanchez-Cortes $3, *$ (D) \\ 1 Dipartimento di Scienze e Tecnologie Agro-Alimentari, Univerisità di Bologna, V.le Fanin 40, 40127 Bologna, \\ Italy; giulia.zanasi91@gmail.com (G.Z.); ornella.francioso@unibo.it (O.F.) \\ 2 School of Technology and Applied Sciences, Sao Paulo State University (UNESP), \\ Presidente Prudente 19060-900, SP, Brazil; carlos.constantino@unesp.br \\ 3 Instituto de Estructura de la Materia (IEM-CSIC), Serrano 121, E-28006 Madrid, Spain; \\ mvca@iem.cfmac.csic.es \\ * Correspondence: rafael.gon.fis@gmail.com (R.J.G.R.); s.sanchez.cortes@csic.es (S.S.-C.)
}

Citation: Zanasi, G.; Rubira, R.J.G.; Francioso, O.; Cañamares, M.V.; Constantino, C.J.L.; Sanchez-Cortes, S. Sensing Atrazine Herbicide Degradation Products through Their Interactions with Humic Substances by Surface-Enhanced Raman Scattering. Chemosensors 2021, 9, 148. https://doi.org/10.3390/ chemosensors 9060148

Academic Editor: Maria Grazia Manera

Received: 25 April 2021

Accepted: 9 June 2021

Published: 16 June 2021

Publisher's Note: MDPI stays neutral with regard to jurisdictional claims in published maps and institutional affiliations.

Copyright: (c) 2021 by the authors. Licensee MDPI, Basel, Switzerland. This article is an open access article distributed under the terms and conditions of the Creative Commons Attribution (CC BY) license (https:/ / creativecommons.org/licenses/by/ $4.0 /)$.

\begin{abstract}
In this work, we have developed a simple method to carry out the quantitative analysis of deethylhydroxyatrazine (DEHA), the most abundant metabolite of atrazine herbicide (ATZ), based on the surface-enhanced Raman scattering technique. Since this ATZ product can undergo $\mathrm{pH}$-dependent tautomerization, a previous characterization of the DEHA vibrational spectrum was accomplished. This study consisted of the Raman scattering study, both experimental and theoretical, of the enolic and ketonic tautomers of this molecule. SERS spectra were recorded at different $\mathrm{pH}$ in order to assess the effect of the metal surface in nanoparticles along with the $\mathrm{pH}$ on the structure of DEHA and to find the optimal experimental conditions of the quantitative detection of DEHA. Additionally, the interaction of DEHA with two types of humic acid reference standards, the Elliot humic and leonardite humic ones, was also performed by SERS. This interaction was conducted with two different objectives: to evaluate the interaction mechanism of the ATZ degradation product with humic substances and to check if this interaction can modify the sensitivity of the SERS detection of DEHA. The results presented in this study have clearly demonstrated that SERS spectroscopy is a very powerful technique for characterizing DEHA and other triazine sub-products at a very low concentration in water and also for analyzing the interaction of these important pollutants with humic substances.
\end{abstract}

Keywords: atrazine; pesticide degradation; SERS; humic acids

\section{Introduction}

s-Triazines have been considered one of the most effective selective herbicides used for the control of a variety of weeds in agricultural crops [1,2]. Among chloro-s-triazine derivatives, atrazine (2-chloro-4-ethylamino-6-isopropylamino-s-triazine) is the most applied throughout the world [3,4]. Although s-triazines have been banned in most countries, their residues persist in the soil and may constitute a significant source of environmental contamination [5]. The fate of triazines in the soil is recognized to be controlled by interaction with a variety of components possessing a wide range of typical chemical reactivity (ionic, polar, and non-polar). Ionic and polar sites interact with the polar functional groups of triazine even though these sites also have a high affinity for water and compete with the same sites present in the soil surface. Non-polar sites on the soil surface readily interact with the non-polar portions of triazine molecules (alkyl side chains). In the specific case of atrazine, this pesticide exhibits a great affinity for soil organic matter, and the sorption process is correlated positively with organic $C$ content [6]. The contribution of soil organic 
matter to atrazine sorption appears to be considerable. In particular, the affinity of atrazine is much more pronounced regarding the soil solid phase if the soluble organic matter content is very high [7].

The role of humic substances (HS) in the atrazine sorption on soils has been investigated in several studies [8-10]. Humic acids (HA) are a prominent fraction of HS that have been hypothesized to interact with atrazine via proton transfer, electron transfer, and hydrophobic interactions. However, no clear and definitive result has yet been obtained. This is primarily explained by the great complexity and heterogeneity of humic substances. In this regard, a critical knowledge of the interactions is fundamental for an accurate estimate of the environmental impact of the pollutants released and the effectiveness of remediation strategies $[11,12]$.

Another crucial issue concerning the effects of these kinds of pesticides is their stability once released into the environment. It has been shown that atrazine degradation is high and can proceed mainly via the soil microbial activity $[13,14]$, even though chemical hydrolysis and redox reactions are implicated [15]. The degradation is influenced not only by the chemical property of atrazine but also by its interaction with the soil component or environment [16].

Abiotic degradation of triazine herbicides is also possible through regular hydrolysis, which proves to be relatively fast in acid and alkaline soils, but is relatively slow in neutral soils $[17,18]$. Moreover, redox reactions are affected by oxygen present in minerals $(\mathrm{Fe}$, $\mathrm{Mn}$, and Co) and HS. Free radicals existing in HS may also act as oxidants promoting the oxidation reactions $[19,20]$. Adsorption on soil particle surfaces also contributes to the breakdown of herbicides [21]. Furthermore, in a recent work, we reported several degradation mechanisms that atrazine and prometryn can undergo under different chemical conditions [22].

Atrazine was found to be mainly degraded by dealkylation, leading to deethylatrazine (DEA) and deisopropyl-atrazine (DIA), and also by hydroxylation, resulting in the hydroxyl-atrazine (OHA), deethylhydroxyatrazine (DEHA), and deisopropylhydroxyatrazine (DIHA) metabolites $[14,23,24]$. Although all these metabolites are produced by biodegradation, some of them (desethyl-atrazine and desisopropyl-atrazine) were obtained by photocatalytic trials [25]. In soil, these metabolites tend to establish hydrophobic interactions with soil organic matter, which, by aging, form residues irreversibly bound by covalent binding or chemical incorporation into organic matter [26].

Methods for determining atrazine metabolites typically demand complicated analytical procedures mainly depending on extraction efficiencies, including types of extraction solvents, and additional cleaning of the extracts [27]. However, the polar nature of the resulting products represents a great disadvantage in the analysis and detection of all the products by conventional techniques, and there are therefore limitations regarding the detection of degradation products [24]. Accordingly, the development of alternative sensitive methods for analyzing such compounds is extremely helpful. Such methods need to be extremely selective to detect very low concentrations of atrazine degradation products, including the presence of humic substances.

Raman spectroscopy has been frequently employed in the analysis of triazine herbicides thanks to the different fingerprints characterizing each of the original and degradation products, which have a similar chemical structure [24]. However, the low sensitivity of normal Raman suggests the use of a surface-enhanced Raman scattering (SERS) technique that exhibits high selectivity and sensitivity properties and, thus, represents a good alternative to study triazines and their degradation products [20]. This technique is extremely sensitive and can give rise to an average enhancement of the Raman signal of about $10^{6}$, reaching, in some extreme cases, an enhancement of $10^{10}$ in scattering efficiency over normal Raman scattering [28]. Therefore, SERS can nowadays be considered a powerful analytical technique for herbicide analysis. The enhancement of the Raman intensity is based on the adsorption of the analyzed molecules on nanostructured noble metal surfaces. 
The electric field enhancement is associated with localized surface plasmon resonance (LSPR) induced on the metal surface [28-31].

The main objective of the present study is to develop an ultrasensitive and selective analytical method for triazine degradation products using the SERS technique. Although SERS was applied for the detection of atrazine, no work has been performed to identify the degradation products of triazines. This is surprising in light of the fact that most triazines immediately degrade to other products in aqueous media, especially at high temperature and low $\mathrm{pH}$ values.

Specifically, in this study, we focused on the most abundant metabolite of atrazine (ATZ), identified as atrazine-desethyl-2-hydroxy or deethylhydroxyatrazine (DEHA, Figure 1), and its structural modifications under different $\mathrm{pH}$ values that lead to tautomeric forms. Another important issue concerns the stability and the fate of DEHA as a result of its interaction with soil humic substances. For this reason, the interaction of DEHA with two humic acid reference standards, Leonardite humic acid (LHA) and Elliot soil humic acid (EHA), was investigated based on the specific fingerprints provided by SERS. These two HAs were selected based on the different structure and functional groups' content.

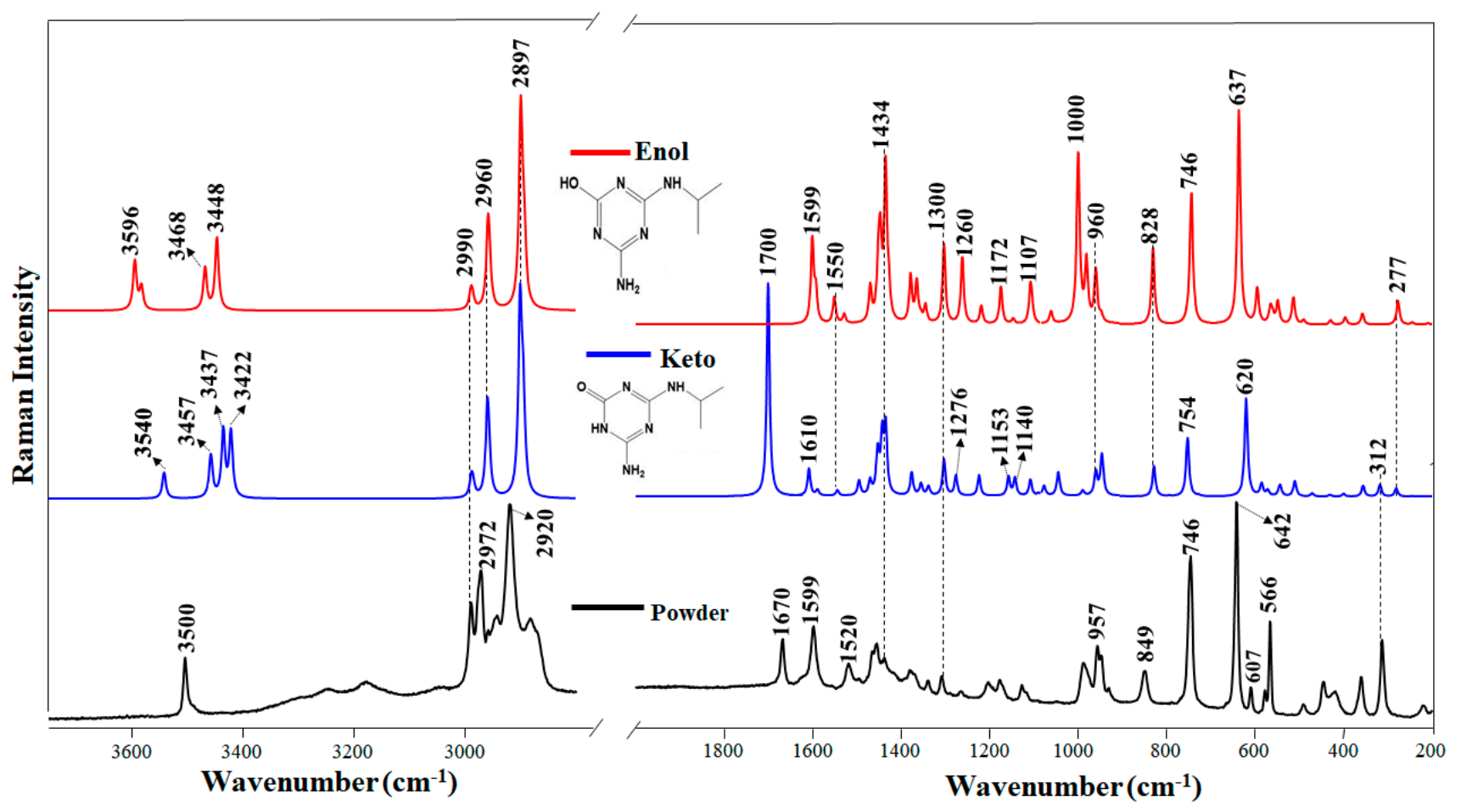

Figure 1. Raman spectrum of the DEHA powder and DEHA calculated spectra in keto and enol form.

\section{Materials and Methods}

\subsection{Reagents}

$\mathrm{AgNO}_{3}, \mathrm{Na}_{3} \mathrm{C}_{6} \mathrm{H}_{5} \mathrm{O}_{7}(\mathrm{CT})$, and $\mathrm{NH}_{2} \mathrm{OH} . \mathrm{HCl}$ were purchased from Sigma-Aldrich (Saint Louis, MO, USA). Atrazine-desethyl-2-hydroxy (DEHA- ${ }_{6} \mathrm{H}_{11} \mathrm{~N}_{5} \mathrm{O}, \mathrm{PESTANAL}^{\circledR}$, analytical standard) was purchased from Sigma-Aldrich (Saint Louis, MO, USA). Highly purified standard of Leonardite humic acid (LHA, code 1S104H) and Elliot soil humic acid (EHA, code 1S102H) were bought from the International Humic Substances Society (IHSS, Denver, CO, USA).

\subsection{Preparation of Silver Nanoparticles (AgNPs)}

Hydroxylamine AgNPs were obtained by the method previously described [32]. The method consists of adding $300 \mu \mathrm{L}$ of sodium hydroxide $(1.0 \mathrm{~mol} / \mathrm{L})$ in $90 \mathrm{~mL}$ of hydrochloride hydroxylamine aqueous solution $\left(1.66 \times 10^{-3} \mathrm{~mol} / \mathrm{L}\right)$ under stirring. Then, $10.0 \mathrm{~mL}$ of 
Ag nitrate aqueous solution $\left(1.0 \times 10^{-2} \mathrm{~mol} / \mathrm{L}\right)$ was added to this mixture, drop by drop. Finally, the colloidal suspension remained $10 \mathrm{~min}$ under stirring and at room temperature for at least $24 \mathrm{~h}$ before starting the experiments.

\subsection{Sample Preparation}

Stock aqueous solutions of DEHA were prepared at a final concentration of $10^{-2} \mathrm{M}$. The mother solutions of HAs were prepared by dissolving $1 \mathrm{mg}$ of each HA in $1 \mathrm{~mL}$ of $1 \mathrm{M} \mathrm{NaOH}$. Different $\mathrm{pH}$ values of HA solutions were obtained by adding $0.1 \mathrm{~N} \mathrm{NaOH}$ or $0.1 \mathrm{~N} \mathrm{HCl}$. Ultrapure water $(\geq 18.0 \mathrm{M} \Omega \mathrm{cm})$ was utilized in the preparation of all solutions. All chemical reagents were analytical grade.

\subsection{UV-Vis Spectra}

Samples for the extinction spectra of the individual colloidal solution of AgNPs were obtained by adding $2500 \mu \mathrm{L}$ of water and $500 \mu \mathrm{L}$ of AgNPs colloidal solution to a quartz cuvette; other samples were prepared by adding $2480 \mu \mathrm{L}$ of water, $500 \mu \mathrm{L}$ of AgNPs colloidal solution, and $20 \mu \mathrm{L}$ of $\mathrm{NaCl} 0.05 \mathrm{M}$ to a quartz cuvette to study the nanoparticles' aggregation. UV-vis extinction spectra of all the samples (AgNPs, AgNPs + DEHA, and AgNPs + $\mathrm{NaCl}+$ DEHA) are shown in the Supplementary Material (Figure S1). UV-vis extinction spectra of Ag NPs suspensions were recorded with a Shimadzu 3600 spectrometer using quartz cells, $1 \mathrm{~cm}$ optical path. Samples were diluted in Milli-Q water $(v / v)$.

\subsection{Raman and SERS Sample Preparations}

A sample of solid DEHA was used to obtain a normal Raman spectrum. Samples for SERS measurements were prepared by adding $20 \mu \mathrm{L}$ of the analytes solution (DEHA $10^{-2} \mathrm{~mol} / \mathrm{L}$ and HA $1 \mathrm{mg} / \mathrm{mL}$ ) to $980 \mu \mathrm{L}$ of AgNPs suspensions. The HA solutions were obtained by dissolving $1 \mathrm{mg}$ of the corresponding humic fraction in $1 \mathrm{~mL}$ of tri-distilled water. The activation was performed by adding $20 \mu \mathrm{L}$ of $\mathrm{NaCl} 0.05 \mathrm{M}$ to the silver colloid. The final concentrations of DEHA in the sample ranged from $10^{-4}$ to $10^{-7} \mathrm{~mol} / \mathrm{L}$. Samples for SERS measurements of DEHA/humic acids' interaction were prepared as follows: $30 \mu \mathrm{L}$ of DEHA at different concentrations (from $10^{-2}$ to $10^{-7} \mathrm{~mol} / \mathrm{L}$ ) were added to $50 \mu \mathrm{L}$ of HA at different concentrations (from 1 to $0.1 \mathrm{mg} / \mathrm{mL}$ ). Then, $20 \mu \mathrm{L}$ of this solution was added to $980 \mu \mathrm{L}$ of AgNPs; $\mathrm{NaOH}$ was used for changing the $\mathrm{pH}$ of the solutions. Raman and SERS spectra were recorded with a Renishaw Raman In Via Spectrometer (Renishaw Iberica S.A.U., Gavá, Spain), equipped with a Leica microscope and an electrically refrigerated CCD camera, using the 532 (Nd:YAG) excitation line and a power of $2 \mathrm{~mW}$. The SERS spectra were the result of one scan registered with an integration time of $10 \mathrm{~s}$ and a resolution of $2 \mathrm{~cm}^{-1}$.

\subsection{Quantitative Analysis}

Quantitative analysis was performed by averaging the SERS intensity values obtained from a set of three measurements for each concentration. The water band was applied as the internal standard. The limit of detection (LOD) was calculated using the Origin Pro 7.5 software (Origin Lab, Northampton, MA, USA) and estimated using 3 $3 /$ sensitivity, where $\sigma$ is the blank noise intensity, and sensitivity (b) is interpreted as the slope of the fitted curve [33,34]. The values for calculating the LOD are listed in Table 1.

Table 1. Analytical parameters obtained from the calibration curve and used in the LOD calculations.

\begin{tabular}{cccc}
\hline Sample & $\begin{array}{c}\text { Sensitivity } \\
\left(\boldsymbol{I}_{\boldsymbol{s} \boldsymbol{m}} \boldsymbol{K}_{\boldsymbol{a d}}\right)\end{array}$ & \multicolumn{2}{c}{ Limit of Detection } \\
\hline EHA + DEHA & 3273 & $4.73 \times 10^{-8} \mathrm{~mol} / \mathrm{L}$ & $8 \mathrm{ppb}$ \\
DEHA & 2149 & $3.42 \times 10^{-8} \mathrm{~mol} / \mathrm{L}$ & $6 \mathrm{ppb}$ \\
LHA + DEHA & 33 & $7.70 \times 10^{-7} \mathrm{~mol} / \mathrm{L}$ & $130 \mathrm{ppb}$ \\
\hline
\end{tabular}




\subsection{Theoretical Raman Calculations}

Normal Raman spectrum of DEHA was calculated with the B3LYP hybrid functional and $6-31+G(d, p)$ one-electron atomic basis set. DEHA geometry was previously optimized using the same functional and basis set. All the calculations were performed in vacuum conditions. Thus, DEHA was considered a single molecule without intermolecular interactions. Calculations were carried out using the Gaussian 09 computational chemistry package [35]. Detailed assignments of the vibrational normal modes were based on the best fit comparison of the wavenumbers of calculated and experimental Raman bands. Several scaling factors were used to reduce the frequency deviations between the calculated wavenumbers and the experimental ones: 0.95 for wavenumbers above $1650 \mathrm{~cm}^{-1}, 0.9648$ between 1650 and $1100 \mathrm{~cm}^{-1}$, and 1.0117 below $1100 \mathrm{~cm}^{-1}$ [36].

\section{Results and Discussion}

\subsection{Morphology of AgNPs: Extinction Spectra and TEM}

The extinction spectra of the $\mathrm{Ag}$ colloid in the absence and presence of the $\mathrm{NaCl}$ and DEHA show a plasmon with a maximum at $403 \mathrm{~nm}$ (Figure S1). In addition, a band appears at high wavelengths around $596 \mathrm{~nm}$, which shows that DEHA in the presence of $\mathrm{NaCl}$ salt causes the aggregation of the colloid. Possibly this factor with the addition of HA helped in the detection of DEHA. These Ag nanoparticles synthesized with the reducing agent hydroxylamine are well studied in the literature. Our group has already shown in previous studies [37] that these types of nanoparticles with plasmon around 403 have an average size of about $26 \pm 2 \mathrm{~nm}$, with a predominant spherical shape. The inset in Figure S1 confirms the diameter mentioned in the work and shows the predominantly spherical shape of the Ag nanoparticles using a transmission electron microscopy (TEM) image.

\subsection{Experimental and Theoretical Raman Spectra of DEHA}

Figure 1 shows the Raman spectrum of solid DEHA and the corresponding calculated spectrum of the enol structure. The main wavenumber positions and assignments of this spectrum are shown in Table S1. However, as DEHA molecules can undergo keto-enol tautomerism, we also calculated the theoretical Raman spectrum of the keto form (Figure 1). Since Raman has not been applied up to now to the study of these triazine products, the attribution of vibrational bands of Raman spectra was performed on the basis of the theoretical analysis along with the comparison with molecules structurally similar that were characterized by Raman. Calculations made for the two different tautomers that can render the atrazine (ATZ) products (enol and keto) were employed to better understand the dynamic of these molecules at different $\mathrm{pH}$. Previous works based on the use of the infrared technique have shown that metabolites resulting from the atrazine degradation were subjected to a conversion from enol to keto form with the decreasing of the $\mathrm{pH}$ [38].

The keto-enol tautomerism has an evident effect on the Raman spectrum that provides a fingerprint for every form. In the case of peripheral moieties, the most involved group is that of keto, with a ureide structure, which can be identified by the intense band seen in the experimental spectrum of the powder at $1670 \mathrm{~cm}^{-1}$, which corresponds to the calculated band in the keto form appearing at $1700 \mathrm{~cm}^{-1}$. The latter band is assigned to the $\mathrm{C}=\mathrm{O}$ stretching motion $(v(\mathrm{C}=\mathrm{O}))$. Other bands associated with the ureide structure appear in the $1200-1300 \mathrm{~cm}^{-1}$ region of the calculated spectrum, which are attributed to C-N stretching according to the theoretical calculation, while the band at $1610 \mathrm{~cm}^{-1}$ is attributed to $v(\mathrm{C}=\mathrm{N})$ vibrations.

The enol structure of DEHA is characterized by the disappearance of the $v(\mathrm{C}=\mathrm{O})$ band $\left(1700 \mathrm{~cm}^{-1}\right)$ and the corresponding changes affecting the ureide moiety in the 1200 $1300 \mathrm{~cm}^{-1}$ region. In addition, an intense band appearing at $3596 \mathrm{~cm}^{-1}$ is attributed to $v(\mathrm{O}-\mathrm{H})$ stretching in the enol structure, while the other bands appearing at 3468 and $3448 \mathrm{~cm}^{-1}$ are attributed to $v(\mathrm{~N}-\mathrm{H})$ motions.

The vibrations corresponding to the triazine ring are also affected by the tautomerization. For instance, the $v(\mathrm{C}=\mathrm{N})$ band of the keto form appearing at $1610 \mathrm{~cm}^{-1}$ moves 
downward to $1599 \mathrm{~cm}^{-1}$ in the enol form due to a higher electronic delocalization, while the ring breathing band at $642 \mathrm{~cm}^{-1}$ undergoes a shift upward. One of the most significant characteristics of DEHA is the prominent ring deformation band (Kekule mode) at $960 \mathrm{~cm}^{-1}$, which is a strong fingerprint of the triazine ring associated with the enol structure, and that it is intensified in the enol form.

The analysis of the calculated Raman vibrational spectra of enol and keto DEHA suggests that the solid atrazine derivative has contributions from both the keto and enol structures. The intense band at $3500 \mathrm{~cm}^{-1}$ is attributed to the $v(\mathrm{O}-\mathrm{H})$ motion, while the broad bands seen in the $3000-3400 \mathrm{~cm}^{-1}$ can be attributed to the $v(\mathrm{~N}-\mathrm{H})$ motions, that are involved in H-bonds. The presence of intense bands at 3500, 1599, 746, and $642 \mathrm{~cm}^{-1}$ points out the presence of the enol form, since they correlate well with similar bands in the enol calculated spectrum. On the other hand, the presence of bands at 1670, 1520, and 607 indicates that the keto form is also contributing to the final structure of DEHA in the solid state.

The Raman of DEHA in an aqueous solution or ethanol could not be obtained due to the weak Raman efficiency of this molecule. The only way to observe a vibrational Raman spectrum in solution and low concentration was SERS on silver NPs.

\subsection{SERS Spectra of DEHA at Different $p H s$}

Figure 2a shows the SERS spectra of DEHA on AgNPs at different pHs. The changes observed in the SERS spectra in relation to the solid are attributed to the interaction of DEHA with the metal surface. The adsorption of DEHA on silver nanoparticles is necessary for the intensification of the Raman, but the adsorption in this case implies an actual chemisorption on NPs that can change the structure of the molecule. In particular, the disappearance at $\mathrm{pH}$ above 8.0 of the bands associated with the keto structure in the ureide moiety at 1620 and $3500 \mathrm{~cm}^{-1}$ of the solid DEHA suggests the tautomerization of the molecule from the keto to the enol form upon adsorption on the surface, in agreement with the calculated spectra of DEHA.

The tautomerization of DEHA is mainly caused by the $\mathrm{C}=\mathrm{O}$ interaction of the keto DEHA form with the metal. This bond is highly involved in the chemisorption of the molecule on the silver surface of the nanoparticle because of its electron donor activity (Figure 2b). Silver atoms on the surface have empty orbitals in the highest electron levels that account for their high tendency to accept electrons to complete the almost filled shells. In this respect, the chemisorption of oxygen is possibly due to the paired electron configuration and the formation of coordination bonds between the metal and the keto group [39]. The chemisorption and interaction of the $\mathrm{C}=\mathrm{O}$ group with the metal occur through the formation of an $\mathrm{Ag}-\mathrm{O}$ bond, which usually falls in the spectral region between $200-300 \mathrm{~cm}^{-1}$ [28]. In Figure 2a, the band at $205 \mathrm{~cm}^{-1}$ indicates the interaction between oxygen atoms of DEHA and the metal nanoparticle. Similar bands were also observed in the case of other O-containing molecules chemisorbed on Ag surfaces [40-44].

The $\mathrm{pH}$ also plays an important role in the adsorption and tautomerization of DEHA on AgNPs, two processes that are of the highest relevance when studying the behavior and fate of this molecule in soils at a $\mathrm{pH}$ below 7.5; the bands corresponding to the ureide form (those at 1620,1522, and $642 \mathrm{~cm}^{-1}$ ) are seen again, due to the subsequent tautomerization to the keto form on the surface induced by the $\mathrm{pH}$ decrease. The band at $1620 \mathrm{~cm}^{-1}$ is attributed to $v(\mathrm{C}=\mathrm{O}) /\left(v(\mathrm{C}=\mathrm{N})\right.$ vibrations. In addition, the band at $1522 \mathrm{~cm}^{-1} \mathrm{can}$ be also attributed to the keto structure according to the theoretical Raman calculations, and it can be attributed to the C-N stretching in the ring, the deformation of the $\mathrm{N}-\mathrm{H}$ and $\mathrm{C}-\mathrm{H}$ bonds, and the scissoring of the $\mathrm{NH}_{2}$ group (Table S1). 
DEHA SERS spectra $\left(10^{-4} \mathrm{~mol} / \mathrm{L}\right)$ at different $\mathrm{pHs}$
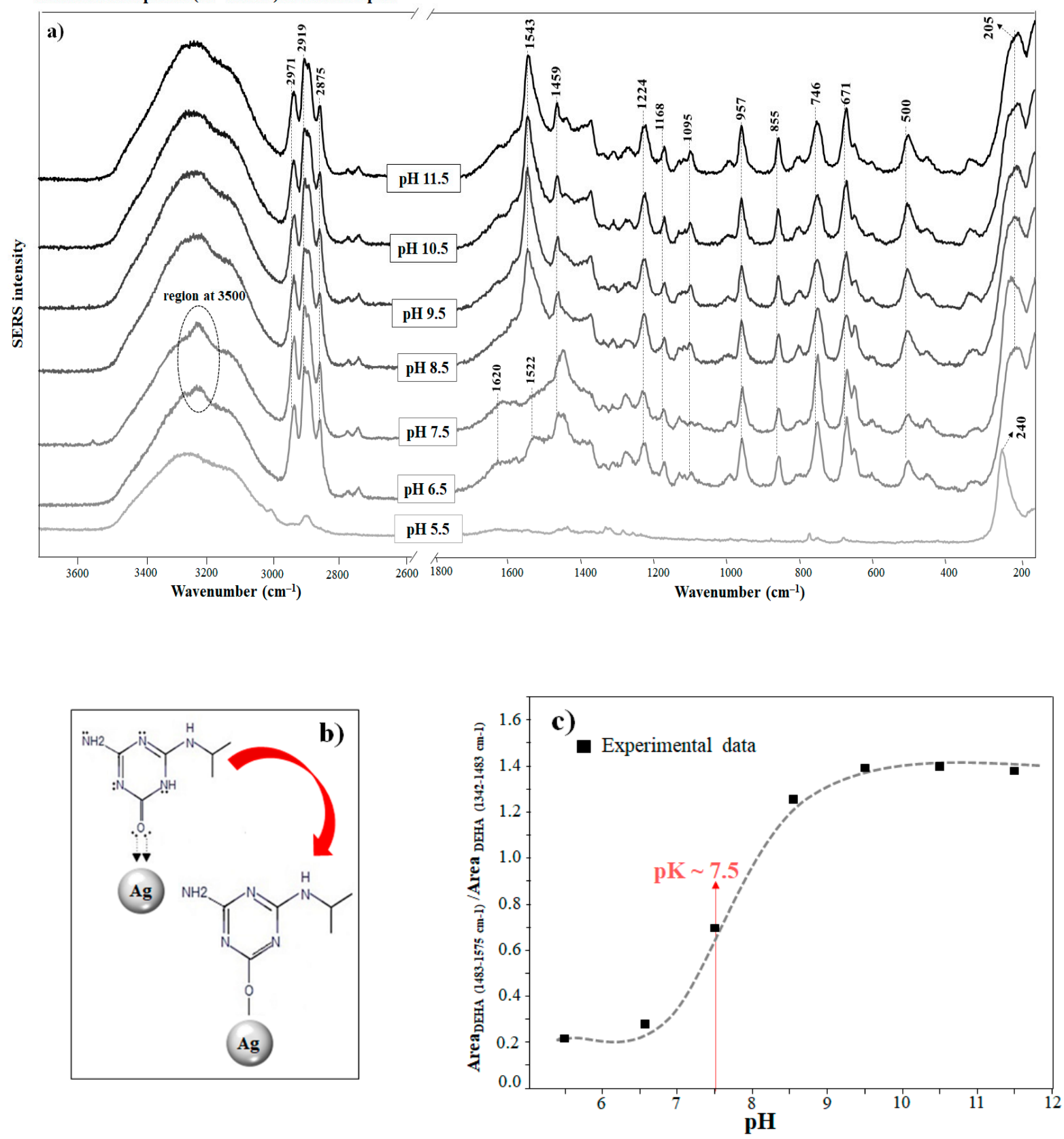

Figure 2. (a) DEHA SERS spectra $\left(10^{-4} \mathrm{~mol} / \mathrm{L}\right)$ obtained at different pHs (the spectra are normalized separately). (b) Adsorption mechanism on the silver surface in the keto and enol form. (c) Variation of the integrated areas of band at different $\mathrm{pHs}$

Therefore, a simultaneous existence of DEHA in the enol and keto forms on the surface is possible. Finally, at pH below 5.5, the intensity of the SERS spectra is weakened due to the much lower affinity of the keto form. The variation of SERS intensity with the $\mathrm{pH}$ is evidently related to the ionization of DEHA at different $\mathrm{pH}$ as well as the different affinities of the enol and keto forms and on the silver surface. The $\mathrm{pH}$ dependence of tautomerization has also been reported for other triazine degradation byproducts such as cyanuric acid [45] and ammeline [45,46]. For hydroxypropazine, a structurally related molecule, it has also been reported that a decrease in $\mathrm{pH}$ increased its solubility due to tautomerization and protonation effects [47]. Therefore, hydroxyatrazine also changed from an enol to a keto form and then to a protonated keto form as the $\mathrm{pH}$ decreased [48]. 
Thus, the higher affinity of DEHA towards the silver surface at alkaline $\mathrm{pH}$ indicates that enol DEHA molecules have a higher affinity for this surface. This $\mathrm{pH}$-dependence must be highly considered when implementing an analytical method of triazine pesticides and their sub-products based on the SERS technique.

The interaction of DEHA with Ag NPs under the enol form at alkaline $\mathrm{pH}$ leads to important structural variations on this structure that makes the SERS spectrum very different from that observed in the solid or the solution. For instance, the intense band at $1598 \mathrm{~cm}^{-1}$ present in the Raman spectrum (Figure 1) of the powder and assigned to $v(\mathrm{C}=\mathrm{N})$ bonds is strongly shifted to $1543 \mathrm{~cm}^{-1}$ in the SERS spectrum at alkaline $\mathrm{pH}$. This shift demonstrates the presence of the enol form, as this band is also shifted in the calculated spectra from the enol tautomer to the keto one (Figure 1, Table S1). This shift is related to the higher delocalization of aromatic electrons that decreases the bond order of the $\mathrm{C}=\mathrm{N}$ bonds in going from the keto to the enol tautomers. An important feature of SERS at alkaline $\mathrm{pH}$ is the appearance of the medium band at $1224 \mathrm{~cm}^{-1}$. This band can be assigned to $v(\mathrm{C}-\mathrm{O}) / \gamma(\mathrm{C}-\mathrm{N})$ of the enolate form of DEHA (Table S1), which is formed by the interaction with the silver nanoparticles or at basic $\mathrm{pH}$.

The coordination of DEHA with the metal has a significant effect on the ring structural vibrations. For instance, the band appearing at $566 \mathrm{~cm}^{-1}$ in the Raman spectrum of the powder (Figure 1), attributed to ring deformation $(\mathrm{NCN})$ coupled with $\delta\left(\mathrm{NH}_{2}\right)$, undergoes a down shift to $500 \mathrm{~cm}^{-1}$ when interacting with silver (Figure 2a). Conversely, the more intense band appearing at $642 \mathrm{~cm}^{-1}$ in the powder spectrum (Figure 1), attributed to the ring breathing motion of DEHA, moves to $671 \mathrm{~cm}^{-1}$ in the SERS. A similar effect was observed in the SERS of the structural related melamine [49]. All these structural vibrations together with the Kekulé band at $957 \mathrm{~cm}^{-1}$, assigned to $\delta(\mathrm{CNC}) / \delta(\mathrm{NCN})$ ring deformations, undergo a clear weakening in the SERS. These effects highlight the existence of a strong interaction of DEHA with the metal, which strongly affects the structural motions of the full molecule.

As the $\mathrm{pH}$ decreases, the interaction mechanism changes, since the interacting model of DEHA is directly linked to the chemical structure of the adsorbate. The predominance of the keto form at a $\mathrm{pH}$ below 7.5 leads to the adoption of an alternative interaction model based on the formation of ion pairs between protonated amino groups and chloride ions existing on the silver surface, as demonstrated by the existence of an intense $\mathrm{Ag}-\mathrm{Cl}$ stretching band at $240 \mathrm{~cm}^{-1}$. This new model implies a weaker ring-surface interaction, as indicated by the down shift of the ring breathing mode to $637-671 \mathrm{~cm}^{-1}$. On the other hand, the enhancement of bands corresponding to the aliphatic isopropyl chain (1459, $746 \mathrm{~cm}^{-1}$ ) similarly points to the existence of an interaction between the $-\mathrm{NH}_{2}{ }^{+}$- group and the $\mathrm{Cl}^{-}$.

The variation of the SERS intensity of DEHA with the $\mathrm{pH}$ is plotted in Figure 2c. As can be seen, the SERS increases as the $\mathrm{pH}$ rises, and this is related to the increasing adsorption ability of DEHA at alkaline $\mathrm{pH}$. In addition, this is also due to the higher affinity of the enol form, which is more probable at alkaline $\mathrm{pH}$ due to the consequent enolization and the silver surface. The sigmoidal curve plotted in Figure $2 \mathrm{c}$ shows an inflection at $\mathrm{pH}$ 7.5 that may correspond to the $\mathrm{pH}$ at which the enolization starts to grow significantly.

\subsection{Interaction of DEHA with Humic Substances}

Triazine has shown high affinities with both humic and fulvic acids [18,50-53]. The interaction ability of humic substances regarding pesticides is enhanced due to the presence of both highly polar and aliphatic groups in their structure [18]. These functional groups present in HS are believed to be the key factor in the dynamics of triazines in soil through the interaction by different mechanisms, both hydrophilic and hydrophobic (Figure 3a). A general description of the interactions between the DEHA and HS is complicated due to their extreme heterogeneity; for this reason, the studies were focused on two IHSS standards: Elliot soil humic acids (EHA) and the Leonaredite humic acids (LHA). EHA are characterized by a high content of acidic functional groups $[54,55]$ and aliphatic moieties 
compared to LHA, where there is a higher content of aromatic moieties than aliphatic ones [56]. Thus, these HS represent a good reference model for studying the interaction of triazine products with two different structural organic substances. Figure $3 \mathrm{~b}$ displays the SERS spectrum of DEHA and the difference spectrum of the DEHA/EHA complex (displayed in Figure S2) and that of non-complexed DEHA (at a concentration $10^{-4} \mathrm{M}$ ). The $\mathrm{pH}$ of all suspensions was maintained at 8.5 in order to promote the interaction between DEHA and humic substances.
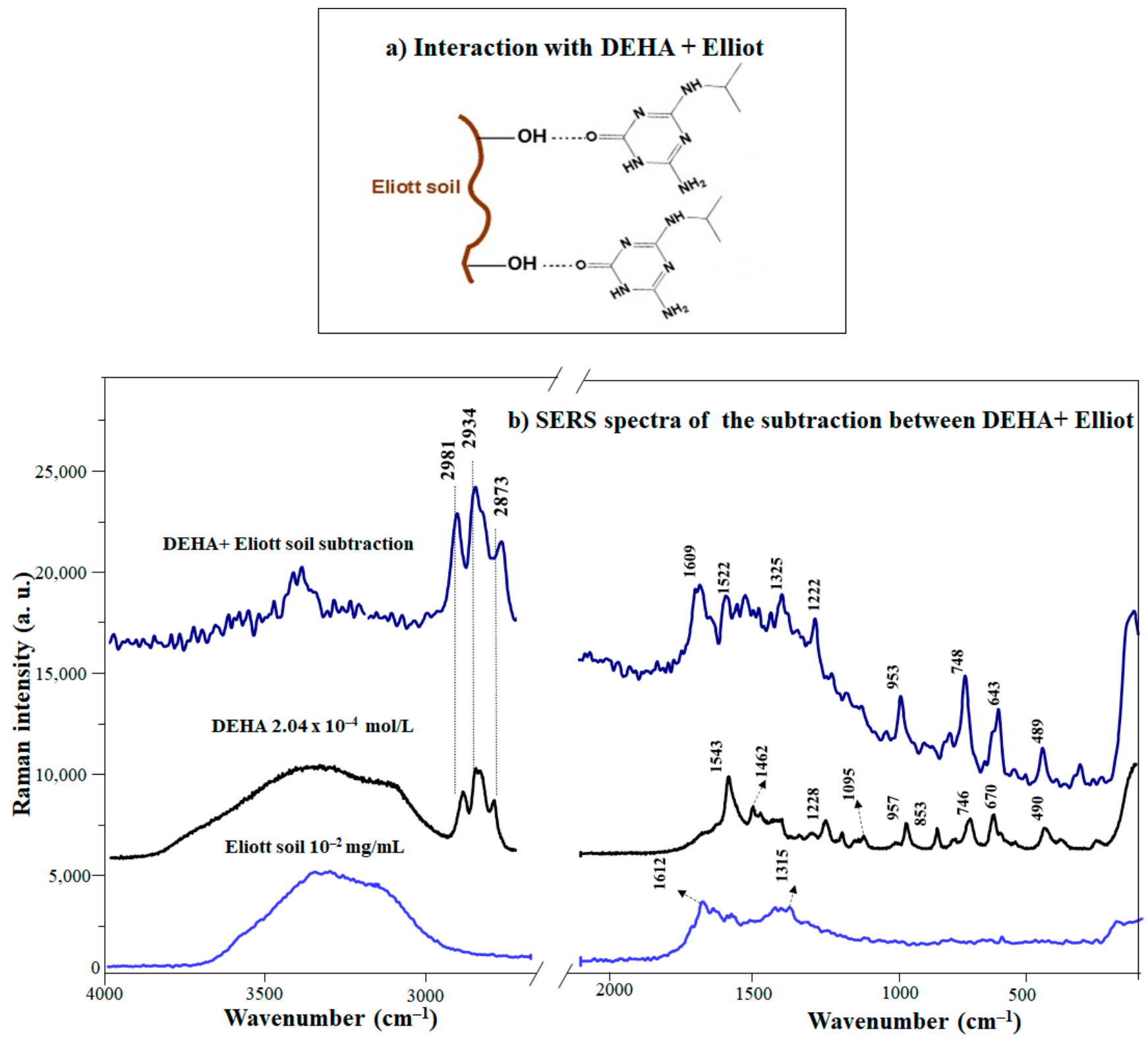

Figure 3. (a) Mechanisms of interactions between DEHA in the presence of EHA $(1 \mathrm{mg} / \mathrm{mL})$. (b) SERS spectrum of the DEHA/EHA complex and non-complexed DEHA.

The comparative analysis of the difference spectrum between the DEHA/EHA complex and the SERS of DEHA reveals the presence of bands corresponding to the keto form, specifically those observed at 3500,1609, and $1522 \mathrm{~cm}^{-1}$. In addition, the bands attributed to the isopropyl chain $\left(748,2873,2934\right.$, and $2981 \mathrm{~cm}^{-1}$ ) are also enhanced (Figure 3b). Finally, further evidence of the increasing importance of the keto structure in DEHA/EHA complexes is that the difference ring breathing band appearing at $643 \mathrm{~cm}^{-1}$ is also seen in the keto form of SERS spectra in free DEHA (Figure 2a). The increase of the keto form 
in complexes with EHA is attributed to the establishment of $\mathrm{H}$-bonds between the high amount of existing acidic functional groups in the EHA $(-\mathrm{OH},-\mathrm{COOH})$ of EHA [18,57] and amino and keto groups in the keto DEHA (Figure 3a).

A focal point of the present study is that the interaction between DEHA and HA depends primarily on the original chemical composition of $\mathrm{HA}$ and the $\mathrm{pH}$ of the system. In particular, HAs change their conformation from coiling $(\mathrm{pH}<5)$ to uncoiling $(\mathrm{pH}>7)$ at different $\mathrm{pH}$ values [58]. Two different interactions between DEHA and LHA/EHA complexes can be inferred: (i) electrostatic interactions and (ii) hydrogen bonding formation. This difference is essentially determined by the composition of the HAs. At alkaline $\mathrm{pH}$, these interactions were particularly strong because of the abundance of negative charges, arising from the deprotonation of the carboxylic groups of the HAs, which favors the DEHA electrostatic attraction.

Figure 4 shows the difference spectrum between the SERS spectra of the DEHA/LHA complex (displayed in Figure S3) and DEHA at pH 8.5. The SERS of LHA is also shown for comparison. As in the case of EHA, the difference spectrum emphasizes better the effect of the HA on the pesticide. In general, the resulting difference bands of the DEHA/LHA complexes correspond to the enol form of DEHA. This is, for instance, corroborated by the presence of characteristic bands of this structure in the SERS difference spectrum observed at 1228 and $1548 \mathrm{~cm}^{-1}$. This fact indicates that DEHA preserves its enolic structure even in the presence of LHA.

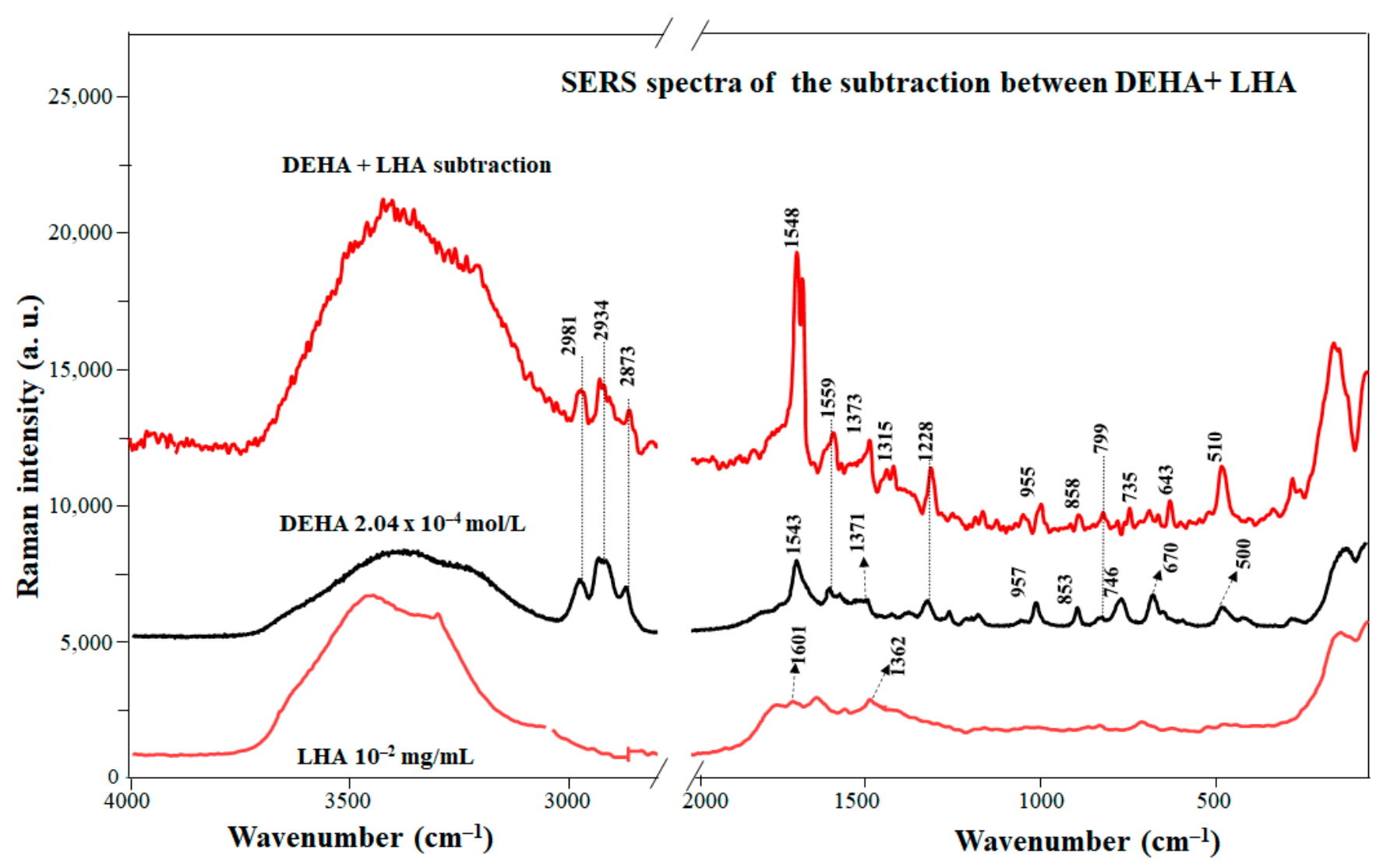

Figure 4. SERS spectrum of the DEHA/LHA complex and non-complexed DEHA.

Nevertheless, some changes can be seen in the bands concerning the ring vibrations. For instance, the positive bands at 510 and $1228 \mathrm{~cm}^{-1}$ and the most intense band at $1548 \mathrm{~cm}^{-1}$ suggest that the triazine ring must be involved in the interaction with LHA. As can be seen, all the ring vibrations shift towards the position that they adopted in absence of the silver surface. This suggests that DEHA molecules could be detached from the surface and linked to the LHA matrix, a result of $\pi-\pi$ stacking between the LHA aromatic 
rings and the aromatic part of DEHA. Furthermore, the importance of the interaction through aromatic moieties explains why the enolic structure, where the aromatic character is notably higher in relation to that of keto, is enhanced in complexes with LHA.

\subsection{Quantitative Analysis}

In the present study, the limit of detection (LOD) was calculated by considering DEHA in the absence and presence of LHA or EHA, respectively, and testing whether humic acids could enhance or diminish the sensitivity of DEHA detection. In order to deduce both the sensitivity and LOD of the SERS analysis of DEHA, the spectra of DEHA were recorded for concentrations ranging from $2.04 \times 10^{-6}$ to $1.63 \times 10^{-4} \mathrm{~mol} / \mathrm{L}$ on AgNPs nanoparticles (Figure S4) at $\mathrm{pH} 8.5$. This $\mathrm{pH}$ value was selected because it corresponds to $\mathrm{pH}$ conditions at which the SERS of DEHA can be measured at optimal intensity for all the analyzed cases. The SERS intensity versus concentration curve (Figure 5) was obtained by calculating the ratio between the area of the $1483-1575 \mathrm{~cm}^{-1}$ region and the integrated area between 3020 and $3750 \mathrm{~cm}^{-1}$ at different DEHA concentrations regarding Figures S2-S4. The curve was plotted considering three experimental measures for every concentration. The curves of Figure 5a can be adjusted to Langmuir isotherms [59,60], where the concentrationdependent calibration curve can be fitted to the following expression:

$$
\theta=\frac{\phi}{\phi_{0}}=\frac{K_{a d} \cdot[\mathrm{DEHA}]}{1+K_{a d} \cdot[\mathrm{DEHA}]}
$$

where $\varphi_{0}$ is the maximum number of molecules that can be adsorbed on the AgNPs surface and $\varphi$ is the number of molecules adsorbed, while $K_{a d}$ is the DEHA adsorption constant. Here [DEHA] is the concentration of DEHA molecules in the bulk, but we can assume that it actually corresponds to the total number of molecules, due to the fact that the number of molecules adsorbed on the metal surface is negligible in comparison to the total one. Before the saturation point, the SERS intensity $\left(I_{S E R S}\right)$ exhibits a linear dependence with the number of adsorbed molecules $\left(I_{S E R S}=\alpha \cdot \varphi\right)$ and reaches a maximum when all nanoparticles are completely covered with the adsorbate. At this saturation point, we have $I_{s m}=\alpha \cdot \varphi_{0}$, where $I_{s m}$ is the SERS intensity at saturation. Thus, the $\theta=\frac{\varphi}{\varphi_{0}}$ ratio can be rewritten in terms of the $I_{S E R S} / I_{S m}$ ratio as follows:

$$
\frac{I_{S E R S}}{I_{s m}}=\frac{K_{a d} \cdot[\mathrm{DEHA}]}{1+K_{a d} \cdot[\mathrm{DEHA}]}
$$

and from this we lead to [61]:

$$
I_{S E R S}=\frac{K_{a d} \cdot I_{s m} \cdot[\mathrm{DEHA}]}{1+K_{a d} \cdot[\mathrm{DEHA}]}
$$

The Langmuir-like behavior of the DEHA adsorption suggests that this molecule forms a monolayer onto the AgNPs surface that reaches a saturation at a limit concentration of ca. $1 \times 10^{-5} \mathrm{~mol} / \mathrm{L}$ (Figure 5a). Before this threshold, the SERS intensity follows a linear dependence on the DEHA concentration displayed in Figure $5 \mathrm{~b}$ where the linear dependence can be expressed in the following way: $I_{S E R S}=K_{a d} \cdot I_{S m} \cdot[\mathrm{DEHA}]$. The LOD value was calculated from this linear dependence as shown in Figure $5 b$, by considering the concentration $[\mathrm{DEHA}]_{\mathrm{LOD}}$ at which a relative intensity of $I^{\prime}{ }_{S E R S}=3 \sigma$ is obtained, with $\sigma$ being the standard deviation of the blank measurement [33].

The black line in Figure $5 \mathrm{~b}$ shows the theoretical fitting in the linear region. The LOD calculated for the detection of DEHA corresponded to the concentration of $3.42 \times 10^{-8} \mathrm{~mol} / \mathrm{L}$ $(6 \mathrm{ppb})$, which is in the same range of detection of other works [22,33,62-65].

SERS spectra of DEHA/HA were also obtained at different DEHA concentrations in a range of concentration from $2.04 \times 10^{-6}$ to $1.63 \times 10^{-4} \mathrm{~mol} / \mathrm{L}$, keeping the concentration of the humic acid constant (Figures S3 and S4). 
The LOD and sensitivity $\left(I_{s m} K_{a d}\right)$ of the values for DEHA and the DEHA/HA complex deduced from the latter treatment are shown in Table 1 . As can be seen, the sensitivity of the DEHA detection varied in the following order: EHA/DEHA $>$ DEHA alone $>$ LHA/DEHA. The greater sensitivity achieved with EHA is probably related to the higher degree of affinity of interaction of this substance with DEHA. Thus, this humic acid can attract more DEHA molecules to the surface due to the occlusive effect of the macromolecules, which can act as actual DEHA accumulators, even if some of the pesticide molecules are not so close to the surface. On the contrary, the sensitivity is very much reduced when using LHA. This is attributed to the formation of $\pi-\pi$ interactions between the aromatic rings of LHA and DEHA that may lead to a detachment of DEHA from the surface, which causes a lowering of the SERS intensity.

a) Adsorption isotherm

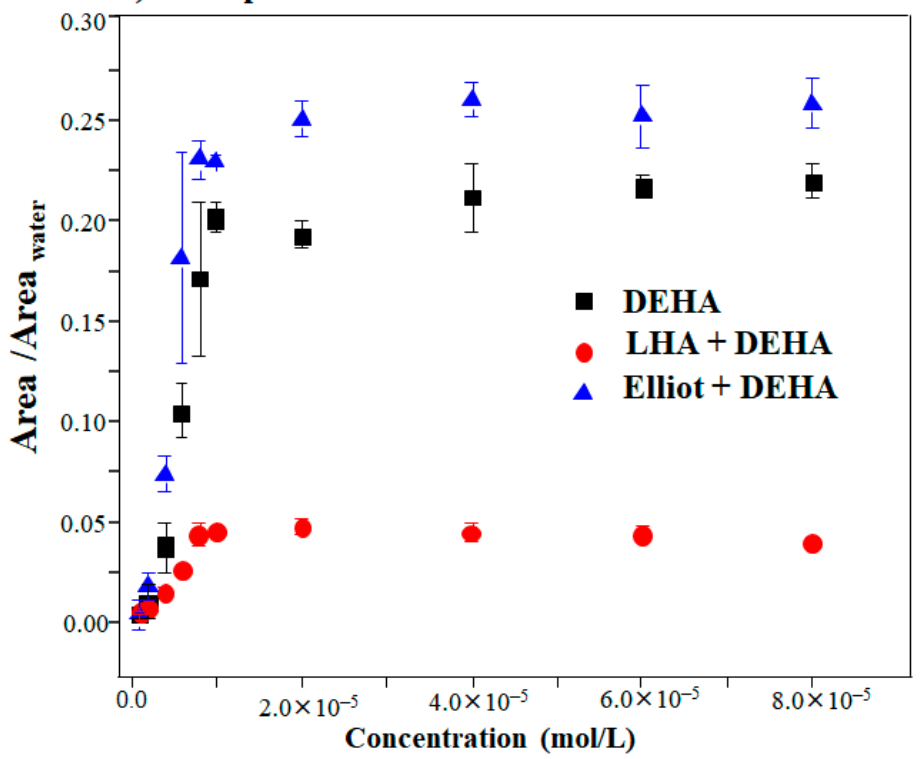

b) Fitting at low concentrations

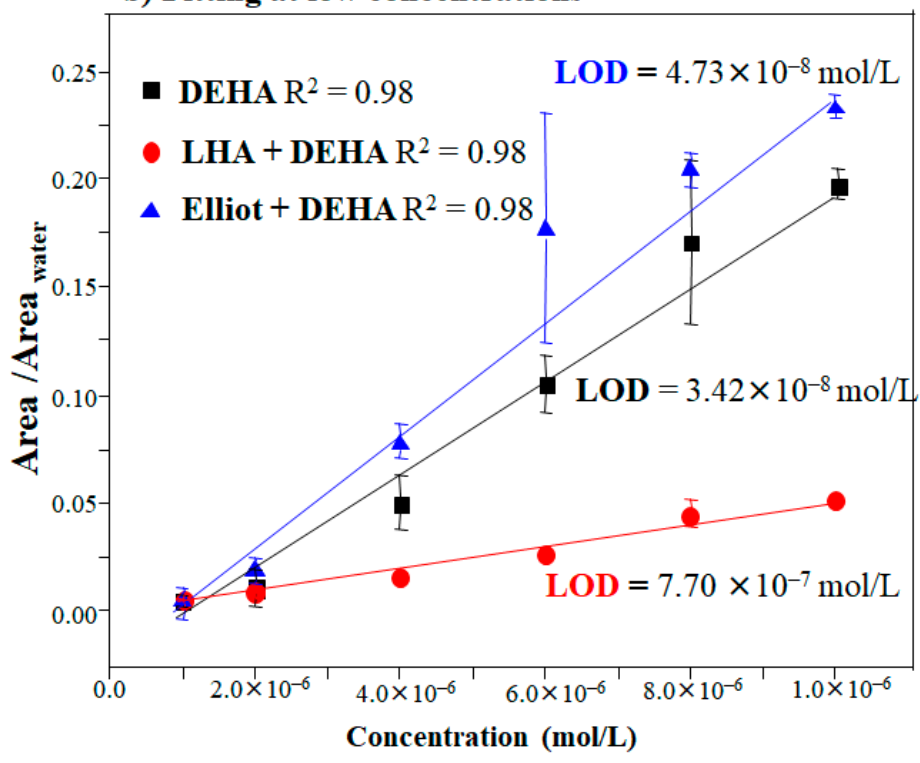

Figure 5. (a) Langmuir-type adsorption isotherm of DEHA in the absence and presence of LHA and EHA onto AgNPs (colloid) and (b) its linear fitting at low concentrations. 


\section{Conclusions}

Although triazines have been banned in many countries, the impact of degradation products on the environment and human health has yet to be elucidated. In the present study, it was shown that DEHA, one of the major degradation products found in the environment, can be sensitively and selectively detected by SERS using AgNPs. A tight $\mathrm{pH}$ dependence of DEHA through protonation and tautomerization of the molecule itself has also emerged, which was found to be well identified by SERS. A relevant issue related to the structure of DEHA that can have a great impact on the environment is its molecular modification by protonation and tautomerization. All of this can be revealed by the vibrational spectra provided by SERS. Theoretical calculation of these spectra was very useful for the identification of key structural bands related to the two DEHA tautomeric forms: enol and keto. From this analysis, it was deduced that solid DEHA has a keto structure.

This molecule is able to interact with the silver surface in AgNPs, leading to an aggregation of the NPs suspension. Moreover, the adsorption mechanism of DEHA on AgNPs takes place through the interaction between the oxygen atom of the keto form of DEHA and the Ag surface. As a consequence of this interaction, DEHA is adsorbed under the enolate form at $\mathrm{pH}$ above 7.5. Under this value, DEHA in the keto form is also seen, and the SERS intensity decreases. Therefore, the DEHA tautomerization and the interaction of DEHA with the metal surface strongly depend on the $\mathrm{pH}$.

The interaction of DEHA with two standard reference humic acids was also developed in an attempt to increase the sensitivity of the technique. SERS spectra in particular revealed a marked difference between the two humic acids' standards in terms of chemical composition and reactivity towards DEHA. In particular, EHA leads to an increase in the sensitivity, while SERS spectra reveal an increase in the keto structure. This phenomenon is closely related to the higher content of oxygenated functional groups that are characteristic of Elliot soil humic acid. By contrast, the interaction of DEHA with LHA reduces the sensitivity of the detection, giving rise to a higher LOD value. In addition, LHA induced major changes in the bands associated with the aromatic ring vibrations, and this is associated with the higher content of aromatic rings present in the leonardite humic acid.

The results presented in this study have clearly demonstrated that SERS spectroscopy is a very powerful technique for characterizing DEHA at a very low concentration in water and also for analyzing the interaction with humic substances.

Supplementary Materials: The following are available online at https:/ / www.mdpi.com/article/10 .3390 / chemosensors9060148/s1, Table S1: Wavenumbers and assignments of theoretical DEHA keto and enolic forms and comparison with the experimental spectra. Figure S1: UV-Vis extinction and TEM characterization of the AgNPs employed in this work. Figure S2: DEHA + LHA SERS spectra at different concentrations of DEHA at $\mathrm{pH}$ 8.5. Figure S3: DEHA + Eliott soil SERS spectra at different concentrations of DEHA at $\mathrm{pH}$ 8.5. Figure S4: DEHA SERS spectra at different concentrations at $\mathrm{pH} 8.5$.

Author Contributions: We declare that each author has made substantial contributions to the conception or design of the work, both the theoretical and experimental works developed for the acquisition, analysis, or interpretation of data developed to create this paper. Likewise, all authors have approved the submitted version and agree to be personally accountable for the author's own contributions and for ensuring that questions related to the accuracy or integrity of any part of the work, even ones in which the author was not personally involved, are appropriately investigated, resolved, and documented in the literature. The contribution of the different authors can be summarized as follows: conceptualization, S.S.-C., C.J.L.C. and O.F.; formal analysis, R.J.G.R. and G.Z.; funding acquisition, S.S.-C., C.J.L.C. and O.F.; investigation, R.J.G.R., G.Z. and M.V.C.; methodology, R.J.G.R., G.Z. and M.V.C.; project administration, S.S.-C., C.J.L.C. and O.F.; resources, S.S.-C. and O.F.; supervision, S.S.-C.; writing-original draft, R.J.G.R. and G.Z.; writing-review and editing, S.S.-C., C.J.L.C., O.F. and M.V.C. We also declare that all authors contributed to revise the sections of the manuscript and read and approved the submitted version. All authors have read and agreed to the published version of the manuscript. 
Funding: This research received funding from the University of Bologna (RFO 2020), FAPESP (2020/05423-0, 2016/09634-0; 2018/04628-8) and the MINECO/FEDER project FIS2017-84318-R.

Institutional Review Board Statement: Not applicable.

Informed Consent Statement: Not applicable.

Data Availability Statement: Not applicable.

Conflicts of Interest: The authors declare no conflict of interest.

\section{References}

1. Barceló, D. Occurrence, handling and chromatographic determination of pesticides in the aquatic environment. A review. Analyst 1991, 116, 681-689. [CrossRef] [PubMed]

2. Yaseen, T.; Pu, H.; Sun, D.-W. Functionalization techniques for improving SERS substrates and their applications in food safety evaluation: A review of recent research trends. Trends Food Sci. Technol. 2018, 72, 162-174. [CrossRef]

3. Rehan, M. Microbial biodegradation of S-triazine herbicides in soil. JCRF 2016, 1, 1-3. [CrossRef]

4. Mandelbaum, R.T.; Wackett, L.P.; Allan, D.L. Mineralization of the S-triazine by stable bacterial mixed cultures. Appl. Environ. Microbiol. 1993, 59, 1695-1701. [CrossRef] [PubMed]

5. Almeida Lage, A.L.; Ribeiro, J.M.; de Souza-Fagundes, E.M.; Brugnera, M.F.; Martins, D.C.d.S. Efficient atrazine degradation catalyzed by manganese porphyrins: Determination of atrazine degradation products and their toxicity evaluation by human blood cells test models. J. Hazard. Mater. 2019, 378, 120748. [CrossRef] [PubMed]

6. Binet, F.; Kersanté, A.; Munier-Lamy, C.; Le Bayon, R.-C.; Belgy, M.-J.; Shipitalo, M.J. Lumbricid macrofauna alter atrazine mineralization and sorption in a silt loam soil. Soil Biol. Biochem. 2006, 38, 1255-1263. [CrossRef]

7. Ben-Hur, M.; Letey, J.; Farmer, W.J.; Williams, C.F.; Nelson, S.D. Soluble and solid organic matter effects on atrazine adsorption in cultivated soils. Soil Sci. Soc. Am. J. 2003, 67, 1140-1146. [CrossRef]

8. Piccolo, A.; Conte, P.; Scheunert, I.; Paci, M. Atrazine interactions with soil humic substances of different molecular structure. J. Environ. Qual. 1998, 27, 1324-1333. [CrossRef]

9. Martin-Neto, L.; Traghetta, D.G.; Vaz, C.M.P.; Crestana, S.; Sposito, G. On the interaction mechanisms of atrazine and hydroxyatrazine with humic substances. J. Environ. Qual. 2001, 30, 520-525. [CrossRef] [PubMed]

10. Abate, G.; Penteado, J.C.; Cuzzi, J.D.; Vitti, G.C.; Lichtig, J.; Masini, J.C. Influence of Humic acid on adsorption and desorption of atrazine, hydroxyatrazine, deethylatrazine, and deisopropylatrazine onto a clay-rich soil sample. J. Agric. Food Chem. 2004, 52, 6747-6754. [CrossRef]

11. Tao, Q.-H.; Tang, H.-X. Effect of dye compounds on the adsorption of atrazine by natural sediment. Chemosphere 2004, 56, 31-38. [CrossRef]

12. Celano, G.; Šmejkalová, D.; Spaccini, R.; Piccolo, A. Interactions of three s-triazines with humic acids of different structure. J. Agric. Food Chem. 2008, 56, 7360-7366. [CrossRef] [PubMed]

13. Mulbry, W.W. Purification and characterization of an inducible s-triazine hydrolase from Rhodococcus corallinus NRRL B-15444R. Appl. Environ. Microbiol. 1994, 60, 613-618. [CrossRef]

14. Lin, C.H.; Lerch, R.N.; Garrett, H.E.; George, M.F. Bioremediation of Atrazine-contaminated soil by forage grasses: Transformation, uptake, and detoxification. J. Environ. Qual. 2008, 37, 196-206. [CrossRef]

15. Lovley, D.R.; Coates, J.D.; Blunt-Harris, E.L.; Phillips, E.J.P.; Woodward, J.C. Humic substances as electron acceptors for microbial respiration. Nature 1996, 382, 445-448. [CrossRef]

16. Olu-Owolabi, B.I.; Diagboya, P.N.; Okoli, C.P.; Adebowale, K.O. Sorption behaviour of pentachlorophenol in sub-Saharan tropical soils: Soil types sorption dynamics. Environ. Earth Sci. 2016, 75, 1494. [CrossRef]

17. Barrett, M.R. The Environmental Impact of Pesticide Degradates in Groundwater. In ACS Symposium Series; Meyer, M.T., Thurman, E.M., Eds.; American Chemical Society: Washington, DC, USA, 1996; Volume 630, pp. 200-225. [CrossRef]

18. LeBaron, H.M.; McFarland, J.E.; Burnside, O.C.; Farland, M.; Burnside, O. The Triazine Herbicides: A Milestone in the Development of Weed Control Technology. In The Triazine Herbicides: 50 Years Revolutionizing Agriculture, 1st ed.; LeBaron, H.M., McFarland, J.E., Burnside, O.C., Eds.; Elsevier: San Diego, CA, USA, 2008; pp. 1-12.

19. Steelink, C.; Tollin, G. Free radicals in soil. In Soil Biochemistry; McLaren, A.D., Peterson, G.M., Eds.; Dekker: New York, NY, USA, 1967; pp. 147-169.

20. Crosby, D.G. Nonbiological degradation of herbicides in the soil. In Herbicides: Physiology, Biochemistry, and Ecology; Audus, L.J., Ed.; Academic Press: New York, NY, USA, 1976; Volume 2, pp. 65-97.

21. Laird, D.A.; Koskinen, W. Triazine Soil Interactions. The Triazine Herbicides: 50 Years Revolutionizing Agriculture, 1st ed.; LeBaron, H.M., McFarland, J.E., Burnside, O.C., Eds.; Elsevier: San Diego, CA, USA, 2008; pp. 275-299.

22. Oliveira, M.J.S.; Rubira, R.J.G.; Furini, L.N.; Batagin-Neto, A.; Constantino, C.J.L. Detection of thiabendazole fungicide/parasiticide by SERS: Quantitative analysis and adsorption mechanism. Appl. Surf. Sci. 2020, 517, 145786. [CrossRef]

23. Mandelbaum, R.T.; Wackett, L.P.; Allan, D.L. Rapid hydrolysis of atriazine to hydroxyatrazine by soil bacteria. Environ. Sci. Technol. 1993, 27, 1943-1946. [CrossRef] 
24. Rubira, R.J.G.; Constantino, C.J.L.; Otero, J.C.; Sanchez-Cortes, S. Abiotic degradation of s-triazine pesticides analyzed by surface-enhanced Raman scattering. J. Raman Spectrosc. 2020, 51, 264-273. [CrossRef]

25. Klementova, S.; Piskova, V. UV Photodegradation of triazines atrazine, simazine and propazine and of atrazine metabolites desethylatrazine and desisopropylatrazine. Res. J. Chem. Environ. 2005, 4, 20-23.

26. Calderbank, A. The occurrence and significance of bound pesticide residues in soil. Rev. Environ. Contam. Toxicol. 1989, 108, 71-103. [CrossRef]

27. Johnson, R.M.; Halaweish, F.; Furmann, J.J. Analysis of atrazine and associated metabolites by reverse-phase high performance thin layer chromatography. J. Liq. Chromatogr. 1992, 15, 2941-2957. [CrossRef]

28. Aroca, R. Surface-Enhanced Vibrational Spectroscopy; John Wiley \& Sons, Ltd.: Chichester, UK, 2006.

29. Moskovits, M. Surface-enhanced spectroscopy. Rev. Mod. Phys. 1985, 57, 783-826. [CrossRef]

30. Wokaun, A. Surface enhancement of optical fields: Mechanism and applications. Mol. Phys. 1985, 56, 1-33. [CrossRef]

31. Guerrini, L.; Campos-Vallette, M.; Domingo, C.; Garcia-Ramos, J.V.; Sanchez-Cortes, S.L.P. Detection of persistent organic pollutants using SERS sensors based on organically functionalized Ag nanoparticles. In Surface Enhanced Raman Spectroscopy; Schlücker, S., Ed.; Wiley: Hoboken, NJ, USA, 2010; pp. 103-128.

32. Cañamares, M.V.; Garcia-Ramos, J.V.; Gómez-Varga, J.D.; Domingo, C.; Sanchez-Cortes, S. Comparative Study of the Morphology, Aggregation, Adherence to Glass, and Surface-Enhanced Raman Scattering Activity of Silver Nanoparticles Prepared by Chemical Reduction of Ag + Using Citrate and Hydroxylamine. Langmuir 2005, 21, 8546-8553. [CrossRef]

33. Furini, L.N.; Sanchez-Cortes, S.; López-Tocón, I.; Otero, J.C.; Aroca, R.F.; Constantino, C.J.L. Detection and quantitative analysis of carbendazim herbicide on Ag nanoparticles via surface-enhanced Raman scattering. J. Raman Spectrosc. 2015, 46, 1095-1101. [CrossRef]

34. International Union of Pure and Applied Chemistry (IUPAC). Available online: https://iupac.org/greeniupac2016/ (accessed on 1 December 2017).

35. Zheng, G.; Lundberg, M.; Jakowski, J.; Vreven, T.; Frisch, M.J.; Morokuma, K. Implementation and benchmark tests of the DFTB method and its application in the ONIOM method. Int. J. Quantum Chem. 2009, 109, 1841-1854. [CrossRef]

36. Merrick, J.P.; Moran, D.; Radom, L. An evaluation of harmonic vibrational frequency scale factors. J. Phys. Chem. A 2007, 111, 11683-11700. [CrossRef] [PubMed]

37. Rubira, R.J.G.; Furini, L.N.; Constantino, C.J.L.; Sanchez-Cortes, S. SERS detection of prometryn herbicide based on its optimized adsorption on Ag nanoparticles. Vib. Spectrosc. 2021, 114, 103245. [CrossRef]

38. Skipper, H.D.; Volk, V.V.; Mortland, M.M.; Raman, K.V. Hydrolysis of atrazine on soil colloids. Weed Sci. 1978, 26, 46-51. [CrossRef]

39. Schmidt, M.; Bréchignac, C. Silver and oxygen: Transition from clusters to nanoparticles. Comptes Rendus Phys. 2016, 17, 481-484. [CrossRef]

40. Dhafer, C.E.B.; Mezni, A.; Smiri, L.S. Surface-enhanced Raman scattering study of Ag-PVP interactions in the biocompatible Ag@PVP nanoparticles. J. Tunis. Chem. Soc. 2017, 19, 152-157.

41. Gao, Y.; Jiang, P.; Liu, D.F.; Yuan, H.J.; Yan, X.Q.; Zhou, Z.P.; Wang, J.X.; Song, L.; Liu, L.F.; Zhou, W.Y.; et al. Evidence for the Monolayer Assembly of Poly(vinylpyrrolidone) on the surfaces of silver nanowires. J. Phys. Chem. B 2004, 108, 12877-12881. [CrossRef]

42. Mdluli, P.S.; Sosibo, N.M.; Revaprasadu, N.; Karamanis, P.; Leszczynski, J. Surface enhanced Raman spectroscopy (SERS) and density functional theory (DFT) study for understanding the regioselective adsorption of pyrrolidinone on the surface of silver and gold colloids. J. Mol. Struct. 2009, 935, 32-38. [CrossRef]

43. Chowdhury, U.K.; Biswas, B.K.; Chowdhury, T.R.; Samanta, G.; Mandal, B.K.; Basu, G.C.; Chanda, C.R.; Lodh, D.; Saha, K.C.; Mukherjee, S.K.; et al. Groundwater arsenic contamination in Bangladesh and West Bengal, India. Environ. Health Perspect. 2000, 108, 393-397. [CrossRef] [PubMed]

44. Baia, M.; Astilean, S.; Iliescu, T. Raman and SERS Investigations of Pharmaceuticals; Springer: Berlin/Heidelberg, Germany, 2008; ISBN 9783540782827.

45. Hirt, R.C.; Schmitt, R.G. Ultraviolet absorption spectra ot derivatives of symmetric triazine-II. Spectrochim. Acta 1958, 12, 127-138. [CrossRef]

46. Boitsov, E.N.; Finkel'shtein, A.I. Optical investigation of the molecular structure of s-triazine derivatives. VI. Ultraviolet absorption spectra of aqueous solution of cyanuric acid derivatives at various pH. Opt. Spectrosc. 1960, 9, 26-28.

47. Ward, T.M.; Weber, J.B. Aqueous solubility of alkylamino-s-triazine as a function of $\mathrm{pH}$ and molecular structure. J. Agric. Food Chem. 1968, 16, 959-961. [CrossRef]

48. Skipper, H.D.; Volk, V.V. Biological and chemical degradation of atrazine in three oregon soils. Weed Sci. 1972, $20,344-347$. [CrossRef]

49. Mircescu, N.E.; Oltean, M.; Chiş, V.; Leopold, N. FTIR, FT-Raman, SERS and DFT study on melamine. Vib. Spectrosc. 2012, 62, 165-171. [CrossRef]

50. Hayes, M.H.B. Adsorption of triazine herbicides on soil organic matter, including a short review on soil organic matter chemistry. In Single Pesticide Volume: The Triazine Herbicides; Gunther, F.A., Gunther, J.D., Eds.; Springer Science and Business Media LLC: New York, NY, USA, 1970; pp. 131-174. [CrossRef]

51. Stevenson, F.J. Organic matter reactions involving herbicides in soil. J. Environ. Qual. 1972, 1, 333-343. [CrossRef] 
52. Senesi, N.; D’Orazio, V.; Miano, T.M. Adsorption mechanisms of s-triazine and bipyridylium herbicides on humic acids from hop field soils. Geoderma 1995, 66, 273-283. [CrossRef]

53. Gorup, L.F. Nanopartículas Coloidais de ouro e Prata e sua Funcionalização com Dibutil-Doicalgenetos. Master's Thesis, Universidade de São Paulo, São Carlos, Brazil, 2010.

54. Korak, J.; Rosario-Ortiz, F.L.; Summers, R.S. Fluorescence Characterization of Humic Substance Coagulation: Application of New Tools to an Old Process. In Advances in the Physicochemical Characterization of Organic Matter, ACS Symposium Serie; Rosario-Ortiz, F.L., Ed.; American Chemical Society: Washington, DC, USA, 2014; Volume 1160, pp. 281-300. [CrossRef]

55. Ritchie, J.D.; Perdue, E.M. Proton-binding study of standard and reference fulvic acids, humic acids, and natural organic matter. Geochim. Cosmochim. Acta 2003, 67, 85-96. [CrossRef]

56. Thorn, K.A.; Folan, D.W.; McCarthy, P. Characterization of the International Humic Substances Society Standard and Reference Fulvic and Humic Acids by Solution State Carbon-13 (13c) and Hydrogen-1 (1h) Nuclear Magnetic Resonance Spectrometry; Water-Resources Investigations Report 89-4196; U.S. Geological Survey: Denver, CO, USA, 1989.

57. Kalouskova, N. Adsorption of atrazine on humic acids. J. Environ. Sci. Health Part B 1989, 24, 599-617. [CrossRef]

58. Corrado, G.; Sanchez-Cortes, S.; Francioso, O.; Garcia-Ramos, J.V. Surface-enhanced Raman and fluorescence joint analysis of soil humic acids. Anal. Chim. Acta 2008, 616, 69-77. [CrossRef] [PubMed]

59. Langmuir, I. The constitution and fundamental properties of solids and liquids. II. Liquids. 1. J. Am. Chem. Soc. 1917, 39, 1848-1906. [CrossRef]

60. Langmuir, I. The constitution and fundamental properties of solids and liquids. Part I. Solids. J. Am. Chem. Soc. 1916, 38, 2221-2295. [CrossRef]

61. Izquierdo-Lorenzo, I.; Sanchez-Cortes, S.; Garcia-Ramos, J.V. Adsorption of beta-adrenergic agonists used in sport doping on metal nanoparticles: A detection study based on surface-enhanced raman scattering. Langmuir 2010, 26, 14663-14670. [CrossRef] [PubMed]

62. Saleh, N.; Al-Rawashdeh, N.A.F. Fluorescence enhancement of carbendazim fungicide in cucurbit[6]uril. J. Fluoresc. 2006, 16, 487-493. [CrossRef]

63. Liu, B.; Zhou, P.; Liu, X.; Sun, X.; Li, H.; Lin, M. Detection of pesticides in fruits by surface-enhanced raman spectroscopy coupled with gold nanostructures. Food Bioprocess. Technol. 2013, 6, 710-718. [CrossRef]

64. Luo, S.; Wu, Y.; Gou, H. A voltammetric sensor based on GO-MWNTs hybrid nanomaterial-modified electrode for determination of carbendazim in soil and water samples. Ionics 2013, 19, 673-680. [CrossRef]

65. Janči, T.; Mikac, L.; Ivanda, M.; Marušić Radovčić, N.; Medić, H.; Vidaček, S. Optimization of parameters for histamine detection in fish muscle extracts by surface-enhanced Raman spectroscopy using silver colloid SERS substrates. J. Raman Spectrosc. 2017, 48, 64-72. [CrossRef] 